\title{
Patient-centred healthcare, social media and the internet: the perfect storm?
}

\section{Ronen Rozenblum, ${ }^{1}$ David W Bates ${ }^{1,2}$}

${ }^{1}$ Division of General Internal Medicine, Brigham and Women's Hospital and Harvard Medical School, Boston, Massachusetts, USA ${ }^{2}$ Department of Health Policy and Management, Harvard School of Public Health, Boston, Massachusetts, USA

\section{Correspondence to} Dr Ronen Rozenblum, Division of General Internal Medicine, Brigham and Women's Hospital, Harvard Medical School, 1620 Tremont Street, BS-3, Boston, MA 02120, USA; rrozenblum@bics.bwh.harvard. edu

Received 6 December 2012 Accepted 6 December 2012 Published Online First 1 February 2013

\section{SLinked}

http://dx.doi.org/10.1136/ bmjqs-2012-001527

To cite: Rozenblum $\mathrm{R}_{\text {, }}$ Bates DW. BMJ Qual Saf 2013:22:183-186.
Patients are central to healthcare delivery, yet all too often their perspectives and input have not been considered by providers. $^{1}{ }^{2}$ This is beginning to change rapidly and is having a major impact across a range of dimensions. Patients are becoming more engaged in their care and patient-centred healthcare has emerged as a major domain of quality. ${ }^{3-6}$

At the same time, social media in particular and the internet more broadly are widely recognised as having produced huge effects across societies. For example, few would have predicted the Arab Spring, yet it was clearly enabled by media such as Facebook and Twitter. Now these technologies are beginning to pervade the healthcare space, just as they have so many others. But what will their effects be?

These three domains-patient-centred healthcare, social media and the internetare beginning to come together, with powerful and unpredictable consequences. We believe that they have the potential to create a major shift in how patients and healthcare organisations connect, in effect, the 'perfect storm', a phrase that has been used to describe a situation in which a rare combination of circumstances result in an event of unusual magnitude creating the potential for non-linear change. ${ }^{7}$

Historically, patients have paid relatively little attention to quality, safety and the experiences large groups of other patients have had, and have made choices about where to get healthcare based largely on factors like reputation, the recommendations of a friend or proximity. ${ }^{8}$ Part of the reason for this was that information about quality or the opinions of others about their care was hard to access before the internet.

Today, patients appear to be becoming more engaged with their care in general, and one of the many results is that they are increasingly using the internet to share and rate their experiences of health care. They are also using the internet to connect with others having similar illnesses, to share experiences, and beginning to manage their illnesses by leveraging these technologies. While it is not yet clear what impact patients' use of the internet and social media will have on healthcare, they will definitely have a major effect.

Healthcare organisations have generally been laggards in this space-they need to start thinking about how they will use the internet in a variety of ways, with specific examples being leveraging the growing number of patients that are using the internet to describe their experiences of healthcare and how they can incorporate patient's feedback via the internet into the organisational quality improvement process.

\section{PATIENT-CENTRED HEALTHCARE}

Patient-centred healthcare is part of a shift in focus which has drawn increasing interest in recent years, highlighting the importance of incorporating patients' needs and perspectives into care delivery. ${ }^{3}$ The patient's engagement with their care is now considered a key of patientcentred healthcare. One of the most important ways in which this was recognised explicitly was in the Institute of Medicine's Crossing the Quality Chasm Report, in which patient centeredness was considered a dimension of quality, which has helped make this a national priority. ${ }^{3}$ Since then, higher levels of patient centeredness and patient engagement have been shown to be associated with improved clinical outcomes, health service efficiency and positive effects on health-related business metrics. ${ }^{4-12}$

Motivated further by public reports of patient experience, many healthcare 
organisations have strived to become more patient oriented and use patient surveys to assess their progress. $^{4} 613$ The 'Hospital Consumer Assessment of Healthcare Providers and Systems' (HCAHPS) is now required nationally in the USA. ${ }^{14}$ The intent of the HCAHPS initiative was to provide a standardised survey instrument and data collection methodology for measuring patients' perspectives on hospital care. The results are available to the public which enables valid comparisons to be made across all hospitals.

\section{INTERNET USE AND SOCIAL MEDIA}

Use of the internet began to rise rapidly in the mid 1990s and since that time the internet has had an increasingly dramatic impact on culture and commerce. As the number of internet sites has rapidly multiplied and people have learned to use its advantages for a growing range of items, from shopping to finding a good restaurant in a specific area, the use of the internet for health issues has climbed.

Perhaps the major initial use of the internet for healthcare by patients was simply to seek health information. Historically, the information balance was markedly on the side of providers, but the internet clearly affected that. But in many ways, the reference information function of the internet was just the beginning. It is increasingly clear that social media represents a strong force. In addition to the rapidly increasing number of social media tools, the population using them has been growing rapidly together with access to them, and so has the potential size of their impact.

In the past, healthcare was managed mainly via interpersonal communication between the caregiver and the patient, while today, social media offers different modes of interaction. For example, Facebook has become a significant source of healthcare information, such as specific data about health conditions and healthcare facilities, ${ }^{15}$ and blogs have become a powerful communication tool to disseminate health information and engage patients with their care. Researchers have found that, based on the data posted on Twitter, they can detect an array of types of activity, most notably disease outbreaks such as cholera and influenza, ${ }^{16}{ }^{17}$ but more recently, data about issues like headache appearance. ${ }^{18}$

Last but not least, many social media websites today allow customers to describe and rate their experiences with goods and services. Consequently, people are increasingly posting reviews about their care and rating hospitals and even physicians on the internet. ${ }^{19} 20$ Such customer ratings have the potential to become important differentiators among healthcare organisations and providers and may have major future effects on customer behaviour and decisions. While these online patient ratings may or may not be well received by caregivers, ${ }^{21}$ patients themselves may not consider how providers feel about these issues.
A good example of this kind of website is Yelp. com, ${ }^{22}$ which ranks in the top 50 most popular websites in the USA and has more than 50 million monthly unique visitors and around 20 million user ratings available on its site. ${ }^{23}$ Yelp provides online searches for local businesses and allows customers to post reviews and rate a business on a scale of $0-5$. A study that was conducted by researchers at the University of California, Berkeley found that a halfstar rating increase of restaurants in Yelp leads to an increase of 19 percentage points, from 30\% to $49 \%$, of restaurants' sellout rate. ${ }^{24}$ Thus, Yelp ratings scores may change customer choice behaviour and increase business revenues. Customers have begun using the Yelp platform to rate their experiences with healthcare.

Although it is clear that the use of the internet in general and social media in particular will have major effects, it is hard to predict exactly what they will be. Already social networking has proved to be a major benefit for patients, especially those with rare conditions, to share information among themselves. However, just as today it is possible to select restaurants more effectively with Yelp, it is likely that patients will be making decisions about where to get their healthcare through such approaches-though the stakes are considerably higher in healthcare choices.

\section{USING COMMERCIAL WEBSITE RATINGS AND SOCIAL MEDIA TO ASSESS QUALITY}

Two complementary papers tackle the growing trend of internet and healthcare social media use by patients who share and rate their experiences of healthcare and the opportunity to improve quality of care based on these data. In the first, Bardach et $l^{25}$ examine the relationship between commercial website ratings of hospitals (Yelp.com) and traditional hospital performance measures (HCAHPS). In the second, Greaves et $a l^{26}$ discuss the possibility of using various social media sources to detect poor performance before conventional measures of healthcare quality might reveal them.

Bardach et $a l^{25}$ suggest that the ratings posted on the Yelp commercial website may be capturing experiences similar to those driving the more systematically collected HCAHPS ratings, and that improvements in these patient experience measures may be associated with improvements in patient outcomes. They found significant associations between the Yelp star scores and HCAHPS overall scores, with higher Yelp scores correlated with lower mortality rates for myocardial infarction and pneumonia and lower readmission rates for multiple conditions. The magnitude and directions of associations approximate those observed between HCAHPS and these same outcomes. ${ }^{4}{ }^{11}$ These findings reinforce prior work by Greaves and colleagues in England. Greaves et $a l^{27}$ demonstrated significant associations between unsolicited web-based patient 
ratings on the National Health Service (NHS) Choices website, and traditional paper-based survey measures of patients' experiences in hospitals. These associations with clinical outcomes were at least as strong for online ratings as for traditional survey measures of patient experience. Whereas Bardach et al extracted patient ratings from a commercial website (Yelp), Greaves et al used data from the NHS Choices website, ${ }^{28}$ a government website that encourages patients to rate and comment on healthcare organisations. These different types of websites-one commercial and one produced by a national healthcare system - may attract different users. In addition, the websites have different methods for conducting the ratings. Nevertheless, both studies produced similar findings: patients' ratings of their care via the internet correlated with several traditional metrics of quality. Moreover, other previous studies that evaluated online website ratings and traditional survey measurements of patients' experiences have also revealed associations with outcomes. ${ }^{410} 1129$

While these studies are compelling, it is important to note that major potential biases and flaws embedded in rating systems via the internet exist and should be further investigated. People using website ratings may be more extreme (positive or negative) in their views, be younger than the general population and may vary in their health status and many other factors. Perhaps most importantly, 'gaming' may occur, in which providers or their representatives may provide favourable ratings.

In their viewpoint paper, Greaves et $a l^{26}$ outline a novel and timely approach to collect and aggregate patients' descriptions of their experiences on the internet to detect poor clinical care and improve quality. They describe this concept as a 'cloud of patient experience'. They suggest using natural language processing and sentiment analysis to transform unstructured descriptions of patient experience on social networks, blogs, Twitter and hospital review sites into usable measures of healthcare performance. Detection of spikes of specific heath-related events and disease outbreaks based on data posted on social media has been proven to be useful. ${ }^{16-18}$ We agree with the authors that capturing and reporting these data in real time could act as an early warning of insufficient performance.

The authors suggest that such data could soon be used to assess poor clinical care and improve quality. We agree, but we think that there is still an important role for traditional surveys. The new approaches that use social media in particular just have too many potential biases, do not come from representative segments of the population and could too readily be gamed.

Finally, although both papers highlight the value for patients who use the internet and social media to share their experiences and view others, their main focus is on the value for healthcare organisations.
We believe that further in-depth studies should be conducted relating the impact of social media in general and commercial website ratings in particular on healthcare consumers and patients.

\section{CONCLUSIONS}

Patient experiences acquired via the internet and social media appear destined to become of major value to the public, to healthcare organisations and possibly also to regulatory bodies. While we believe they are unlikely to supplant more traditional patient surveys, they will certainly complement them, and should help identify poor care and outstanding care. Thus, in 10 years, the question may not be how to use such data, but how we ever lived without them.

Contributors Both authors (RR and DWB) were involved in the writing of the manuscript. Both authors reviewed and approved the final version of the manuscript.

Competing interests None.

Provenance and peer review Not commissioned; internally peer reviewed.

\section{REFERENCES}

1 Rozenblum R, Lisby M, Hockey P, et al. Uncovering the blind spot of patient satisfaction: an international survey. BMJ Qual Saf 2011;20:959-65.

2 Rozenblum R, Lisby M, Hockey P, et al. The patient satisfaction chasm: the gap between hospital managements and frontline clinicians. BMJ Qual Saf 2013;22:242-50.

3 Institute of Medicine. Crossing the Quality Chasm: A New Health System for the 21st Century. Washington, DC: National Academy Press, 2001.

4 Jha AK, Orav EJ, Zheng J, et al. Patients' perceptions of hospital care in the United States. N Eng J Med 2008;359:1921-31.

5 Berwick DM. A user's manual for the IOM's 'Quality Chasm' report. Health Aff (Millwood) 2002;21:80-90.

6 UK Department of Health. Helping the NHS Put Patients at the Heart of Care: The Patient and Public Engagement Support Programme 2009-2010. London: Department of Health, 2009.

7 Perfect storm. 20 November 2012 at 09:51 UTC. Wikipedia: The Free Encyclopedia. Wikimedia Foundation Inc. http://en. wikipedia.org/wiki/Perfect_storm (accessed 25 Nov 2012)

8 Bates DW, Gawande AA. The impact of the internet on quality measurement. Health Aff (Millwood) 2000;19: 104-14.

9 Meterko M, Wright S, Lin H, et al. Mortality among patients with acute myocardial infarction: the influences of patient centered care and evidence-based medicine. Health Serv Res 2010;45:1188-204.

10 Glickman SW, Boulding W, Manary M, et al. Patient satisfaction and its relationship with clinical quality and inpatient mortality in acute myocardial infarction. Circ Cardiovasc Qual Outcomes 2010;3:188-95.

11 Isaac T, Zaslavsky AM, Cleary PD, et al. The relationship between patients' perception of care and measures of hospital quality and safety. Health Serv Res 2010;45:1024-40.

12 Charmel P, Frampton S. Building the business case for patient centered care. Health Financ Manage 2008;62:80-5. 


\section{Editorial}

13 US Government. The Patient Protection and Affordable Care Act. 2009.

14 HCAHPS: Patient's Perspectives of Care Survey. US Center for Medicaid and Medicare Services. 2012. http://www.cms.gov/ Medicare/Quality-Initiatives-Patient-Assessment-Instruments/ HospitalQualityInits/HospitalHCAHPS.html (accessed 25 Nov 2012)

15 Greene JA, Choudhry NK, Kilabuk E, et al. Online social networking by patients with diabetes: a qualitative evaluation of communication with Facebook. J Gen Intern Med 2011;26:287-92.

16 Signorini A, Segre AM, Polgreen PM. The use of twitter to track levels of disease activity and public concern in the U.S. during the Influenza A H1N1 pandemic. PLoS One 2011;6: e19467.

17 Chunara R, Andrews JR, Brownstein JS. Social and news media enable estimation of epidemiological patterns early in the 2010 Haitian cholera outbreak. Am J Trop Med Hyg 2012;86:39-45.

18 Linnman C, Maleki N, Becerra L, et al. Migraine tweets-what can online behavior tell us about disease? Cephalalgia 2012: Published Online First 7 November 2012. doi:10.1136/ 0333102412465207.

19 Greaves F, Millett C. Consistently increasing numbers of online ratings of healthcare in England. J Med Internet Res 2012;14:e94.

20 Gao GG, McCullough JS, Agarwal R, et al. A changing landscape of physician quality reporting: analysis of patients' online ratings of their physicians over a 5-year period. J Med Internet Res 2012;14:e38.

21 McCartney M. Will doctor rating sites improve the quality of care? No. BMJ 2009;338:b1033.

22 Browse Business Reviews by City. 2012. http://www.yelp.com/ locations (accessed 25 Nov 2012)

23 Tsotsis A. Yelp files for IPO to raise $\$ 100$ million. TechCrunch 25 November 2011.

24 Anderson M, Magruder J. Learning from the crowd: regression discontinuity estimates of the effects of an online review database. Econ J 2012;122:957-89.

25 Bardach N, Asteria-Peñaloza R, Boscardin W, et al. The relationship between commercial website ratings and traditional hospital performance measures in the USA. BMJ Qual Saf 2013;22:194-202.

26 Greaves F, Ramirez CD, Millett C, et al. Harnessing the cloud of patient experience: using social media to detect poor quality healthcare. BMJ Qual Saf 2013;22:251-5.

27 Greaves F, Pape UJ, King D, et al. Associations between internet-based patient ratings and conventional surveys of patient experience in the English NHS: an observational study. BMJ Qual Saf 2012;21:600-5.

28 NHS Choices. 2012. http://www.nhs.uk/Pages/HomePage.aspx (accessed 25 Nov 2012)

29 Greaves F, Pape UJ, King D, et al. Associations between web-based patient ratings and objective measures of hospital quality. Arch Intern Med 2012;172:435-6. 